\title{
Migratory abscess of the middle ear resulting from an odontogenic infection: an unusual case report Kubsad Veerabhadrappa Arun Kumar ${ }^{a}$, Mukesh Soni ${ }^{a}$, Deepa Dhruvakumar ${ }^{b}$
}

Departments of ${ }^{\mathrm{a}}$ Oral and Maxillofacia

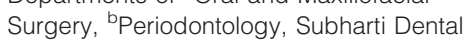
College, Meerut, India

Correspondence to Mukesh Soni, Department of Oral and Maxillofacial Surgery, Subharti Dental College, Meerut, India. Tel: +919997543378;

e-mail: drmukeshsoni@yahoo.com

Received 3 December 2017

Accepted 15 April 2018

The Egyptian Journal of Otolaryngology 2018, 34:355-358
Infections of odontogenic origin are the commonly encountered diseases in their routine practice by head and neck specialists. Their spread to adjacent fascial spaces may follow as sequelae of untreated odontogenic infections, along a predictable route. Unusually, these infections may follow an uncommon path for the spread and may appear at a distant site in contrast to the site of infection, resulting in the formation of a 'migratory abscess'. This case report is entitled to present an unusual and rare case of migratory abscess of the right middle ear in a 20-year old male patient, occurring as sequelae of an odontogenic infection in the right lower second molar and to explain a possible route of transmission of infection in this challenging case presentation.

\section{Keywords:}

middle ear infection, migratory abscess, odontogenic infection, otitis media

Egypt J Otolaryngol 34:355-358

() 2018 The Egyptian Journal of Otolaryngology

1012-5574

\section{Introduction}

Odontogenic infections have been one of the most common diseases in the oral and maxillofacial region $[1,2]$ associated with a mortality rate of $10-40 \%$ [3]. With the advent of modern antibiotics, mortality rates have been reduced significantly [4-6]. Such infections are usually self-limiting $[7,8]$, but sometimes the purulent material may burrow deep into the fascial spaces, form sinus and discharge at a distant site challenging the diagnosis [9].

The propagation of odontogenic infections can be through direct tissue planes, by lymphatic or haematogenous dissemination and depends on the patient's local and systemic factors and on the virulence of the pathogen [10]. The spread of odontogenic infections may be either restrained locally or it may extend beyond to involve primary fascial spaces, which may further spread to more dangerous, secondary spaces. However, rarely, odontogenic infections may take an unusual route and, while showing migration, might appear in an unexpected distant site away from the primary site of infection.

This case report intends to present an unusual case of odontogenic infection with pus discharge from the right ear.

\section{Case history}

A 20- year-old-male patient reported with the chief complaint of pain in the lower right tooth since 1 month, swelling on the right lower side of the face and reduced mouth opening since 6 days and pus discharge intraorally, from the lower right molar region since 4 days and from the right ear since 2 days (Fig. 1). The patient also complained of difficulty in swallowing and mild disturbance in hearing since 2 days. The patient's medical and dental history were nonsignificant. The patient was not used to any adverse habits.

On general examination, the patient's body temperature was elevated and found to be $100^{\circ} \mathrm{F}$. Pulse, respiration rate, and blood pressure were slightly elevated. Local examination was done and the findings were recorded. Extraorally, diffuse swelling was present at the right angle of the mandible which was around $2 \mathrm{~cm}$ in diameter and was tender on palpation along with localised rise in temperature. Right submandibular lymph nodes were palpable and tender. Yellowish purulent pus discharge was seen coming from the right ear which increases upon lying down and was associated with foul odour (Fig. 2). No neurosensory deficit was reported. Patient's consent was obtained.

Intraorally, teeth were examined and mandibular right second molar was found to be grossly carious and tender. Pus was discharging intraorally through a sinus present on the buccal aspect of the mandibular right second molar (Fig. 3). Right anterior faucial

This is an open access journal, and articles are distributed under the terms of the Creative Commons Attribution-NonCommercial-ShareAlike 4.0 License, which allows others to remix, tweak, and build upon the work non-commercially, as long as appropriate credit is given and the new creations are licensed under the identical terms. 
Figure 1

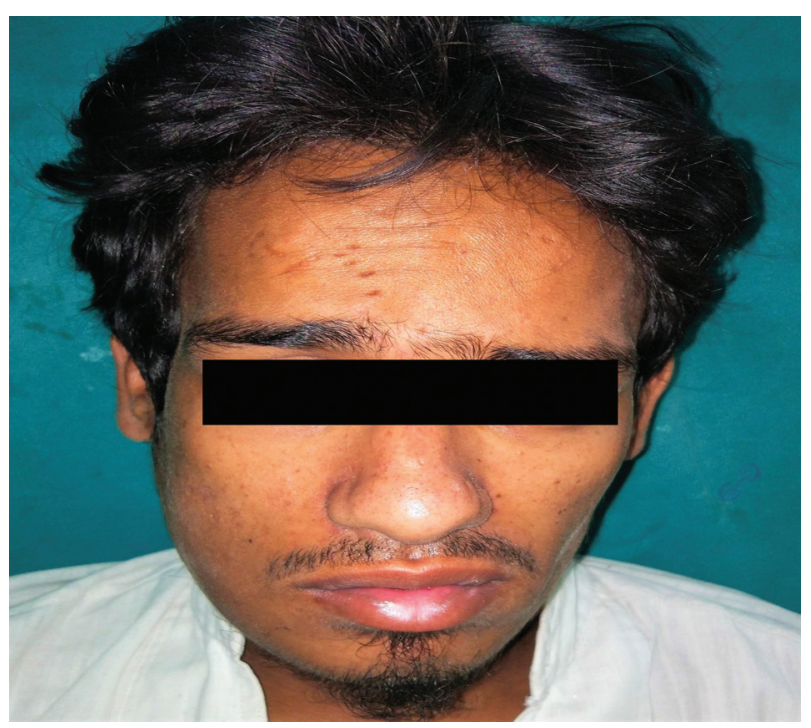

Frontal view showing facial asymmetry.

Figure 2

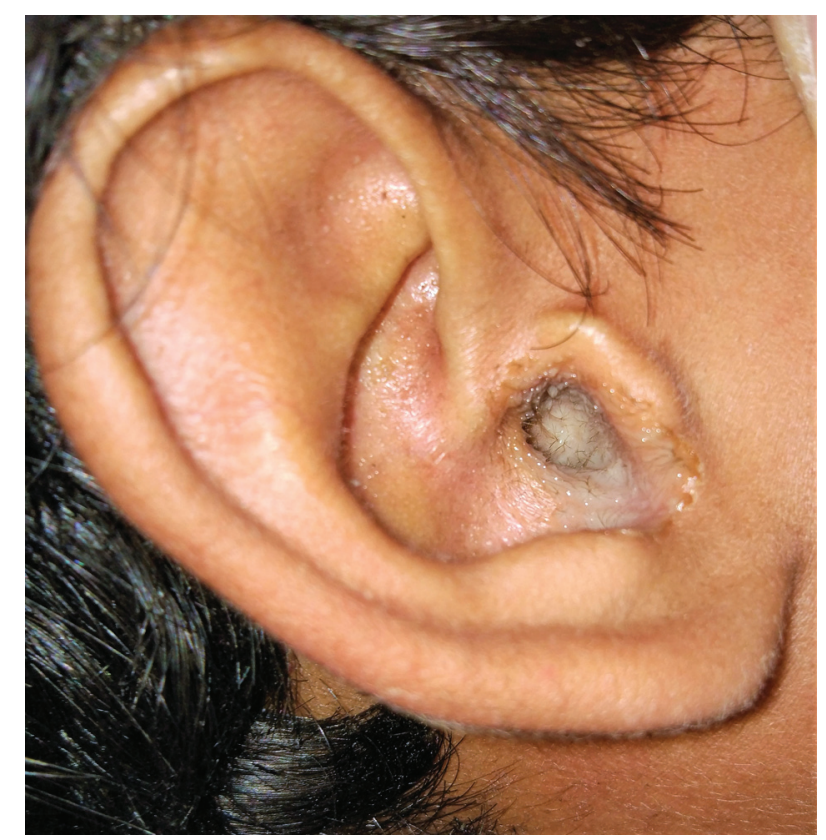

Pus discharge from right ear.

pillar was obliterated with mild deviation of uvula towards the left side. Mouth opening was reduced and measured to be around $11 \mathrm{~mm}$ (Fig. 4). Radiographic examination was done with the help of orthopantomogram and cone beam computed tomography (CBCT) (Figs 5 and 6). Periapical radiolucency was observed with respect to mandibular right second molar and slight radiolucency was observed with respect to the right condylar region in comparison to the contralateral condylar region.
Figure 3

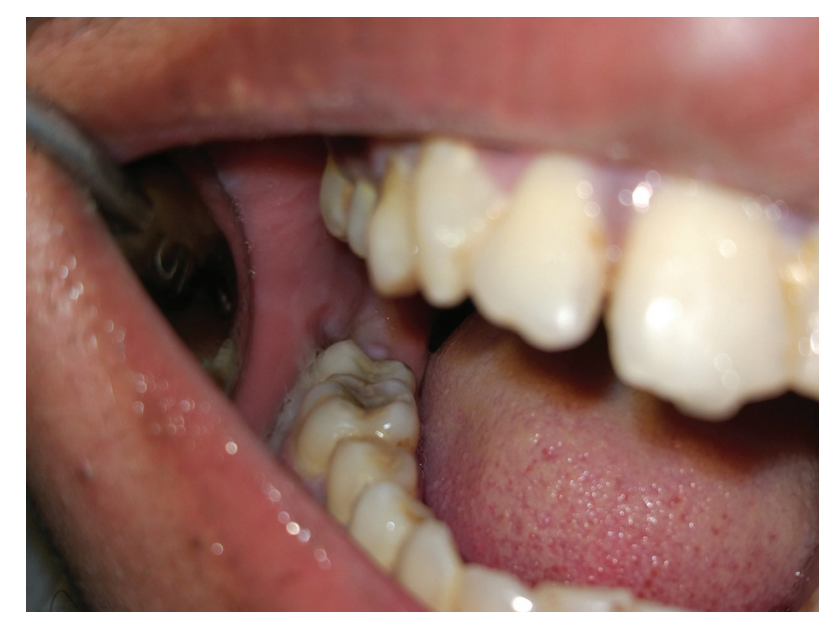

Intraoral pus discharge from buccal aspect of right lower molars.

Figure 4

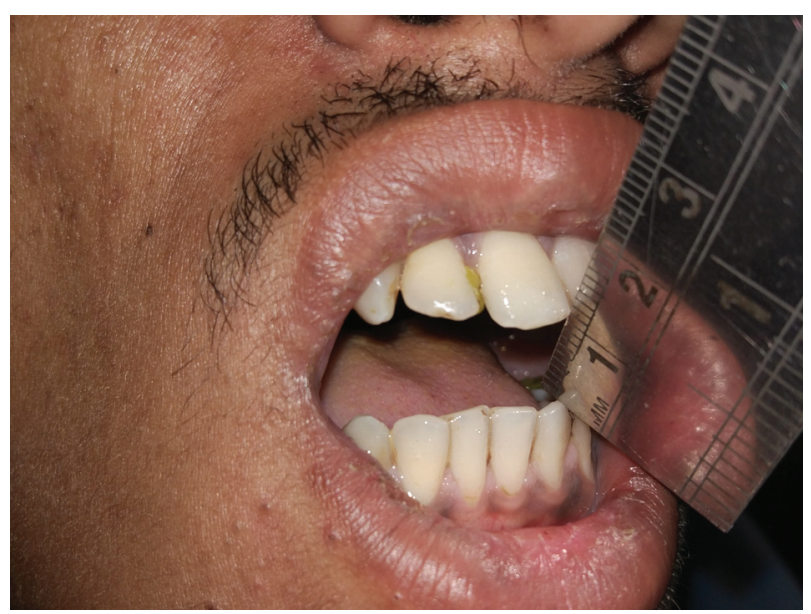

Reduced mouth opening.

Upon ENT examination by a specialist, it was found that active pus discharge from the right ear was present. No sinus formation was observed in the external ear and tympanic membrane was found to be congested showing evidence of pus coming from the middle ear. Mild hearing loss with respect to the right ear was also reported by the patient along with mild pain.

The patient was admitted to the emergency ward and was kept under the cover of antibiotics (third-generation cephalosporins with sulbactum) and NSAIDs. Under the antibiotic cover, right submandibular incision was given and layered dissection was done to reach the right pterygomandibular space. Pus was drained and corrugated drain was placed which was secured with the help of 3-0 black, braided silk (Fig. 7). Dressing was placed and dressing was repeated on alternate days. On 
Figure 5

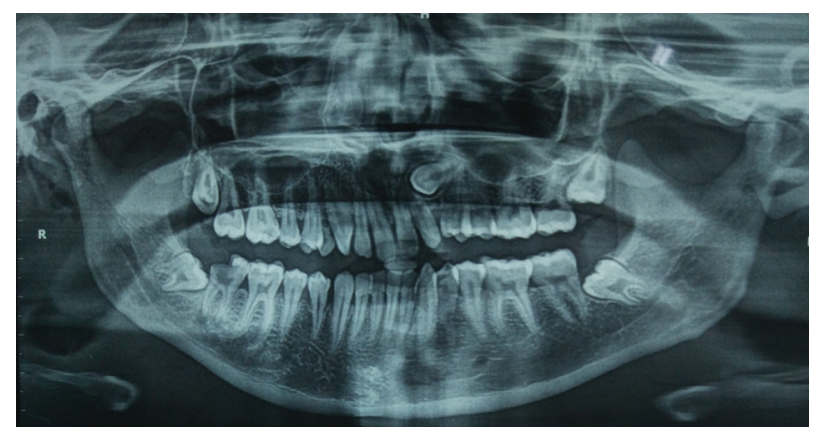

Orthopantomogram.

Figure 6

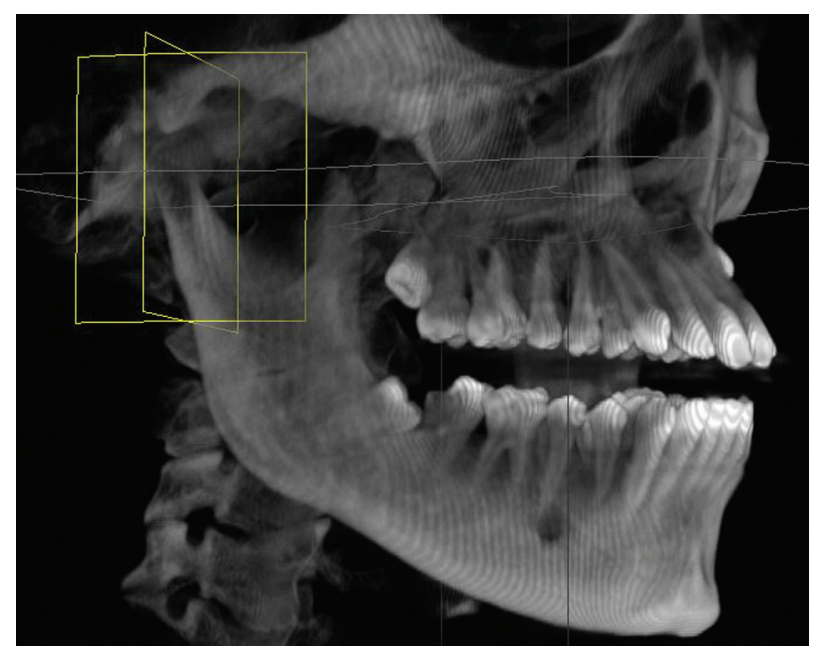

Cone beam computed tomography (CBCT).

the following day, the mandibular right second molar was extracted under local anaesthesia. Patient's mouth opening improvised gradually and swelling subsided within 5 days after the initiation of the treatment. The pus discharge from the ear disappeared completely within first $24 \mathrm{~h}$ of extraoral drainage. Hearing improved considerably there onwards.

\section{Discussion}

Infections originating in a tooth or its supporting structures or in the jaws or soft tissues can spread to distant sites of the head and neck and chest region. The path of an infection could be understood from a thorough knowledge of the anatomy of the head and neck. In the facial region, the loose, fat-containing tissue of the lips and cheeks is continuous. However, it is partially partitioned by the muscles of facial expression, which arise from the bones of the face and which, as variably wide plates, traverse the subcutaneous tissue, to end in the skin. In infections that are not caused by extremely virulent bacteria, the muscles with their thin perimysia play a role in directing the spread of the infection. In this
Figure 7

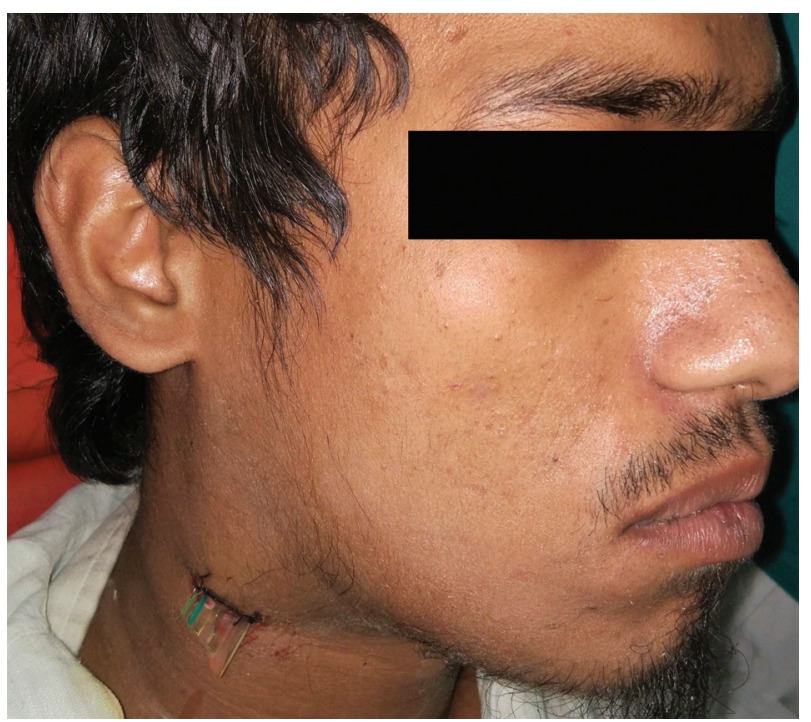

Right submandibular incision and drainage.

respect, dental abscesses that erode and perforate the outer compact lamella of the upper or lower jaw sometimes do not progress toward the oral vestibule, but find their way through the subcutaneous tissue to the skin. Infection propagation may also occur possibly through lymph channels causing metastatic inflammation of lymph nodes or may be through veins, after thrombosis and contained coagulated blood acting as the roadway for invasion of bacteria [11].

Instead of following an expected course of propagation, infections may break down or hydrolyse the tissue barriers to invade the distant sites and form an abscess over there, which can be called as 'migratory abscess'. Although, the formation of cutaneous sinus in odontogenic infections has been reported in the literature [12], an odontogenic infection involving the pterygomandibular space and discharging through the ear has never been reported.

The possible route of infection hypothetically may be understood by the anatomical relationship between pterygomandibular space and temporomandibular joint to the middle ear. In this case, the odontogenic infection from the right mandibular second molar propagated to the right pterygomandibular space, the roof of which is formed by the lateral pterygoid muscle. The fibres of the lateral pterygoid muscle inserts into the capsule of temporomandibular joint (TMJ), articular disc, and finally into the pterygoid fovea at the neck of the condyle. Articular disc connects with the malleus and the middle ear with the help of the discomallear ligament and the anterior mallear ligament. Therefore, the tension created in the pterygomandibular space due 
to the abscess must have been the reason for the pus to travel towards the pterygoid muscle fibres and reach the temporomandibular compartment. From there with possible anatomical weak pterygotympanic suture and the pinto's ligaments the pus has reached the middle ear cavity and discharge through the external ear. The mechanism of anatomical communication between the middle ear cavity and the TMJ is best explained in the fibrous ankylosis due to otitis media. Since we could not find any concrete way by the specialised imaging technique to prove our explanation, this case remains as a special, extraordinary and unusual case presentation which may help the peers to bear in mind while diagnosing such situations.

\section{Conclusion}

Spread of odontogenic infections, most of the time, occurs along a predictable route and to understand the propagation of such infections, a sound knowledge of anatomy is very important. But, sometimes, rather than following a common route, infections may migrate and occur at an unexpected site. Formation of any cutaneous sinus, abscess or pus drainage from a distant site in head and neck region following an odontogenic infection, must alert the doctor to perform a careful thorough examination and deliver appropriate treatment for the resolution of the infection.

\section{Acknowledgements}

The authors acknowledge Dr Ali Atif for his valuable input and help.

\section{Financial support and sponsorship Nil.}

\section{Conflicts of interest}

There are no conflicts of interest.

\section{References}

1 Iwasaki Y, Nagata K, Nakanishi M, Natuhara A, Harada H, Kubota Y, et al. Spiral CT fndings in septic pulmonary emboli. Eur $J$ Radiol 2001; 37:190-194.

2 Zamiri B, Hashemi SB, Hashemi SH, Rafee Z, Ehsani S. Prevalence of odontogenic deep head and neck spaces infection and its correlation with length of hospital stay. Shiraz Univ Dent J 2012; 13:29-35.

3 Britt JC, Josephson GD, Gross CW. Ludwig's angina in the pediatric population: report of a case and review of the literature. Int $\mathrm{J}$ Pediatr Otorhinolaryngol 2000; 52:79-87.

$4 \mathrm{Kim}$ MS, Kim SG, Moon SY, Oh JS, Park JU, Jeong MA, et al. Sepsis developed from an odontogenic infection: case report. J Korean Assoc Maxillofac Plast Reconstr Surg 2011; 33:445-448.

5 Zhang C, Tang Y, Zheng M, Yang J, Zhu G, Zhou H, et al. Maxillofacial space infection experience in West China: a retrospective study of 212 cases. Int J Infect Dis 2010; 14:e414-e417.

6 Amponsah E, Donkor P. Life-threatening oro-facial infections. Ghana Med J 2007; 41:33-36.

7 Zeitoun IM, Dhanarajani PJ. Cervical cellulitis and mediastinitis caused by odontogenic infections: report of two cases and review of literature. J Oral Maxillofac Surg 1995; 53:203-208.

8 Ryan P, McMahon G. Severe dental infections in the emergency department. Eur J Emerg Med 2012; 19:208-213.

9 Bali RK, Sharma P, Gaba S, Kaur A, Ghanghas P. A review of complications of odontogenic infections. Natl J Maxillofac Surg 2015; 6:136-143.

10 Arias-Chamorro B, Contreras-Morillo M, Acosta-Moyano A, Ruiz-Delgado F, Bermudo-Añino L, Valiente-Álvarez A. Multiple odontogenic abscesses. Toracic and abdomino-perineal extension in an immuno competent patient. Med Oral Patol Oral Cir Bucal 2011; 16:e772-e775.

11 Sicher H. Sicher's oral anatomy. 3rd ed. St Louis: The C V Mosby company; 1960.

12 ArunKumar KV, Deepa D. Migratory and misleading abscess of orofacial region. J Indian Soc Periodontol 2015; 19:470-473. 